\title{
Factors associated with adherence to antiretroviral therapy in HIV-infected patients in Kathmandu District, Nepal
}

This article was published in the following Dove Press journal:

HIVIAIDS - Research and Palliative Care

24 June 2014

Number of times this article has been viewed

Rajesh Shigdel'

Elise Klouman ${ }^{2}$

Anita Bhandari²

Luai A Ahmed'

'Department of Health and Care Sciences, ${ }^{2}$ Department of Community Medicine, Faculty of Health Sciences, UiT The Arctic University of Norway, Tromsø, Norway
Correspondence: Rajesh Shigdel

Department of Health and Care Sciences, Faculty of Health Sciences, UiT The Arctic University of Norway, N-9037 Tromsø, Norway Email rajesh.shigdel@uit.no
Purpose: There are a high number of HIV-infected patients receiving antiretroviral therapy (ART) in the Kathmandu District of Nepal, but information on adherence and factors influencing it are scarce in this population. The present study aimed to estimate ART adherence among HIV-infected patients in the Kathmandu District of Nepal, and to determine the factors associated with ART adherence.

Patients and methods: This study included 316 HIV-infected patients attending three ART centers in the Kathmandu District. Information on sociodemographic characteristics, socioeconomic status, and ART use for the previous 7 days was collected via interview. Participants were considered adherent if they reported taking $\geq 95 \%$ of their ART as prescribed. The association between explanatory variables and ART adherence was measured using logistic regression and reported as odds ratios (OR) with 95\% confidence intervals (CI).

Results: Male participants accounted for $64.6 \%(n=204)$. Overall ART adherence was $86.7 \%$. ART adherence in men and women were $84.3 \%$ and $91.1 \%$, respectively. Age (OR 1.04; 95\% CI 1.00-1.09), travel time to ART centers (OR 1.38; 95\% CI 1.12-1.71), history of illegal drug use (OR 3.98; 95\% CI 1.71-9.24), and adverse effects (OR 4.88; 95\% CI 1.09-21.8), were all independently and negatively associated with ART adherence. Use of reminder tools (OR 3.45; 95\% CI 1.33-8.91) was independently and positively associated with ART adherence.

Conclusion: The observed ART adherence in this study is encouraging. Travel time to ART centers, self-reported adverse effects, illegal drug use, and not using reminder tools were the major determinants of ART adherence. Interventions that take these factors into account could further improve ART adherence.

Keywords: ART, adherence, HIV patients, AIDS patients, Asia, Nepal

\section{Introduction}

Antiretroviral therapy (ART) has played an important role in improving the prognosis and quality of life of HIV/AIDS patients, and in reducing the rate of disease progression and death. ${ }^{1-3}$ It has also been reported that increased access to ART can reduce the risk of HIV transmission to sexual partners by $96 \%{ }^{4}$

ART adherence is a primary determinant of the effectiveness of this treatment, and is also considered a major predictor of survival among patients living with HIV/ AIDS. ${ }^{5}$ More than $95 \%$ adherence to ART is required in order to prevent the emergence of resistant HIV strains, obtain long-term HIV suppression, reduce destruction of CD4 cells, increase survival, and improve quality of life ${ }^{6,7}$ However, poor ART adherence can create a dangerous public health problem and limit the effectiveness 
of available HIV treatments. ${ }^{8}$ Poor ART adherence also leads to increased hospitalization rates, increased health care costs, reduced productivity, disruption of families and communities, and morbidity and mortality in low- and middle-income countries. ${ }^{9}$ Moreover, second-line ART regimens can be up to six times more expensive than firstline regimens. ${ }^{10}$ As some patients still show poor ART adherence, this factor remains a major obstacle in the fight against HIV/AIDS. ${ }^{2,7}$ Maintaining optimal ART adherence over a long period of time also poses significant challenges for both patients and health care providers. ${ }^{9}$

Factors affecting ART adherence include patient characteristics, ART regimen, clinical setting, social and environmental factors, and the relationship between patients and their health care providers. ${ }^{6}$ Despite fears to the contrary, ART adherence is high among patients in some low- and middle-income countries. ${ }^{11,12}$

HIV is a concentrated epidemic in Nepal, with an overall prevalence of $0.30 \%$ in the population aged $15-49$ years. ${ }^{13,14}$ In 2011, approximately 50,200 adults and children were living with HIV in Nepal, of whom $28.5 \%$ were women and $58 \%$ were men of reproductive age. ${ }^{14}$ The Government of Nepal started free ART and counseling services in 2004, ${ }^{15}$ and by July 2012 ART coverage had increased to $26.1 \%$ (6,642 adults and 500 children) of 27,363 HIV-infected patients eligible for ART (CD4 $\leq 350)$ at 39 ART centers in 33 different districts. ${ }^{16}$

There are several ART regimens available in Nepal with acceptable antiretroviral potency. Generally, zidovudine (ZDV)/lamivudine (3TC)/neverapine (NVP), ZDV/3TC/ efavirenz (EFV), tenofovir disoproxil fumarate (TDF)/3TC/ NVP, TDF/3TC/EFV, stavudine $(\mathrm{d} 4 \mathrm{~T}) / 3 \mathrm{TC} / \mathrm{EFV}$, and $\mathrm{d} 4 \mathrm{~T} / 3 \mathrm{TC} / \mathrm{NVP}$ are used as first-line regimens, while $\mathrm{TDF} / 3 \mathrm{TC} /$ lopinavir boosted with ritonavir and didanosine/ abacavir/lopinavir boosted with ritonavir are commonly used as the second-line regimens. ${ }^{15}$ Previous studies in Nepal reported $85.5 \%$ ART adherence among attendees of 10 ART centers located in different districts, ${ }^{17} 79 \%$ ART adherence at the Tribhuvan University Teaching Hospital in Kathmandu, ${ }^{18}$ and $84 \%$ ART adherence in the far west of Nepal. ${ }^{19}$

Despite the high number of HIV-infected patients receiving ART in the Kathmandu District of Nepal, information on ART adherence and factors influencing adherence is lacking in this population. The present study aimed to estimate ART adherence among HIV-infected patients attending three ART centers in the Kathmandu District, and to determine the factors associated with ART adherence.

\section{Materials and methods}

\section{Study settings and study population}

The Kathmandu District has six ART centers. A multisite cross-sectional study was conducted at three of them in January to February 2012: the Sukaraj Tropical and Infectious Disease Hospital, Bir Hospital, and the Tribhubhan University Teaching Hospital. The numbers of patients registered and receiving ART across these three centers was 2,240, 102, and 114, respectively. All patients aged 18 years or older who had received ART therapy for at least 3 months prior to study enrollment and were able to give informed consent were eligible for inclusion in the study. A sample size of 316 patients was calculated using formulas described previously, ${ }^{20,21}$ in order to estimate ART adherence with a relative precision of $5 \%$. The number of patients included from each ART center was based on the proportion of patients registered and receiving ART therapy at each center.

Ethical approval was obtained from the Nepal Health Research Council and the National Center for AIDS and STD Control. All participants signed a written informed consent form.

\section{Data collection and variables of interest}

Eligible patients were interviewed for 15-20 minutes by the first author and two ART counselors. The questionnaire used in the present study was adapted from an earlier study, ${ }^{22}$ with slight modifications to fit the norms in Nepal. The questionnaire was translated into Nepali and verified by a second translator. The questionnaire was used to collect sociodemographic information, personal history of ART adherence, and socioeconomic status. Patients' medical records were used to collect information on $\mathrm{CD} 4$ cell counts and ART regimen.

\section{Assessment of adherence}

Adherence was assessed by asking patients to recall their intake of prescribed ART doses in the previous 7 days. In an attempt to minimize recall bias, patients were asked about adherence over the previous day, previous 3 days, and previous 7 days. Self-reported ART adherence was calculated as the ratio of the doses taken during the specific time-period to the total number of ART doses prescribed for the same time-period. The results were expressed as percentages. Patients were considered adherent if they reported taking $95-100 \%$ of their prescribed ART with a delay of no more than 1 hour in the previous 7 days.

\section{Statistical analysis}

The information collected from patients was sorted, coded, and entered in a datasheet created in SPSS version 16 
(SPSS Inc., Chicago, IL, USA). A double-data entry system was used to minimize errors in data entry. The explanatory variables were categorized as follows: age (continuous variable), sex (male/female), marital status (unmarried/ ever-married), educational level (literate/illiterate), occupation (employed/unemployed), monthly income (tertiles), travel time to ART centers (continuous variable), alcohol use in the month preceding the interview (yes/no), illegal drug use in the 6 months preceding the interview (yes/no), and use of reminder tools to take ART (yes/no). The clinical characteristics included the latest available CD4 cell count $\left(>200 / \leq 200\right.$ cells $\left./ \mathrm{mm}^{3}\right)$, ART initiation $(<24 / \geq 24$ months $)$, adverse effects (yes/no), and the number of tablets taken daily (continuous variable).

Differences between adherent and non-adherent patients were tested using the Student's $t$-test and the chi-square test for continuous and categorical explanatory variables, respectively. The strength of association between explanatory variables and ART adherence was measured using logistic regression and was reported as odds ratios (OR) with $95 \%$ confidence intervals (CI). The OR associated with each explanatory variable was calculated first in a univariate model, then in an age- and sex-adjusted model, and finally in a multivariate model including all the variables. The variables with significant or borderline significant associations in the multivariate model were included in the final model. The criterion for statistical significance was set at $P<0.05$.

\section{Results}

Of the 316 participants, $64.6 \%(n=204)$ were men and $35.4 \%$ $(n=112)$ were women. Most of the participants $(n=308)$ were receiving standard first-line ART regimens. A total of $274(86.7 \%)$ participants reported ART adherence, and of these, 268 claimed not to have missed a single dose. On the other hand, 42 (13.3\%) participants reported non-adherence. The most frequently cited reasons for non-adherence were "simply forgot" (80\%) and "busy schedule" (19\%). Other reported reasons for non-adherence included being too sick (11\%), to hide their status from their family and friends (4.7\%), or adverse effects (4.7\%). These percentages overlapped as multiple responses were possible.

Table 1 shows the sociodemographic and clinical characteristics of the study sample by adherence status. Only travel time to ART centers $(P<0.001)$, alcohol use $(P=0.026)$, illegal drug use $(P=0.017)$, self-reported adverse effects $(P=0.005)$, and use of reminder tools $(P<0.001)$ were significantly associated with adherence status. Almost $90 \%$ of the participants reported using some kind of reminder tool to
Table I Sociodemographic and clinical characteristics of HIVinfected patients in the Kathmandu District by ART adherence status, 2012

\begin{tabular}{|c|c|c|c|c|}
\hline Variables & Total & $\begin{array}{l}\text { Adherence } \\
\mathbf{N}(\%) *\end{array}$ & $\begin{array}{l}\text { Non- } \\
\text { adherence } \\
\mathbf{N}(\%) *\end{array}$ & $P$-value \\
\hline \multicolumn{5}{|l|}{ Age (years) } \\
\hline $18-24$ & 44 & $4 I(93.0)$ & $3(7.0)$ & 0.270 \\
\hline $25-34$ & 87 & $78(89.6)$ & $9(10.4)$ & \\
\hline $35-49$ & 148 & $125(84.4)$ & $23(15.6)$ & \\
\hline$>50$ & 37 & $30(81.0)$ & $7(19.0)$ & \\
\hline \multicolumn{5}{|l|}{ Sex } \\
\hline Male & 204 & $172(84.3)$ & $32(15.6)$ & 0.091 \\
\hline Female & 112 & 102 (9I.I) & $10(8.92)$ & \\
\hline \multicolumn{5}{|l|}{ Marital status } \\
\hline Unmarried & 68 & $59(86.7)$ & $9(13.3)$ & 0.945 \\
\hline Married & 154 & $135(87.6)$ & $19(12.4)$ & \\
\hline Divorced & 29 & $25(86.2)$ & $4(13.4)$ & \\
\hline Widow/widowers & 65 & $55(84.6)$ & $10(15.4)$ & \\
\hline \multicolumn{5}{|l|}{ Education level } \\
\hline Illiterate & 56 & $48(85.7)$ & $8(14.3)$ & 0.848 \\
\hline Primary education & 85 & 71 (83.5) & $14(16.5)$ & \\
\hline Secondary education & 99 & $88(88.8)$ & II (II.2) & \\
\hline Higher secondary & 61 & $54(88.5)$ & 7 (1I.5) & \\
\hline University level & 15 & $13(86.6)$ & $2(13.4)$ & \\
\hline \multicolumn{5}{|c|}{ Residence (region of Kathmandu) } \\
\hline Inside valley & 137 & $120(87.5)$ & $17(12.5)$ & 0.686 \\
\hline Outside valley & 179 & $154(86)$ & $25(14)$ & \\
\hline \multicolumn{5}{|l|}{ Occupation } \\
\hline Unemployment & 71 & $58(8 \mathrm{I} .6)$ & $13(18.4)$ & 0.717 \\
\hline Agriculture & 95 & $83(87.3)$ & $12(12.7)$ & \\
\hline Labor work & 53 & $46(86.7)$ & $7(13.3)$ & \\
\hline Business & 68 & $60(88.2)$ & $8(11.8)$ & \\
\hline Office work & 26 & $24(92.3)$ & $2(7.7)$ & \\
\hline Student & 3 & $3(100)$ & $0(0)$ & \\
\hline \multicolumn{5}{|l|}{ Monthly income } \\
\hline Lowest tertile & 99 & $83(83.8)$ & $16(16.2)$ & 0.054 \\
\hline Middle tertile & 107 & $93(86.9)$ & $14(13.1)$ & \\
\hline Highest tertile & 110 & $98(89.1)$ & $12(10.9)$ & \\
\hline \multicolumn{5}{|l|}{ Family size } \\
\hline Nuclear & 208 & I58 (75.9) & $50(24.1)$ & 0.746 \\
\hline Joint & 115 & $88(23.5)$ & $27(76.5)$ & \\
\hline Live alone & 92 & $70(76.0)$ & $22(23.0)$ & \\
\hline \multicolumn{5}{|l|}{ Mode of transmission } \\
\hline Heterosexual & 242 & $212(87.6)$ & $30(12.3)$ & 0.947 \\
\hline Shared needle & 40 & $34(85.0)$ & $6(15.0)$ & \\
\hline Blood transfusion & 12 & $9(75.0)$ & $3(25.0)$ & \\
\hline Unknown & 22 & $19(86.3)$ & $3(13.7)$ & \\
\hline \multicolumn{5}{|c|}{ Cost of travel to ART center } \\
\hline Lowest tertile & 111 & $103(92.7)$ & $8(7.2)$ & 0.054 \\
\hline Middle tertile & 99 & $84(84.8)$ & $15(15.2)$ & \\
\hline Highest tertile & 106 & $87(82.0)$ & $19(18.0)$ & \\
\hline \multicolumn{5}{|c|}{ Travel time to ART center (minutes) } \\
\hline$\leq 60$ & 173 & $161(93.0)$ & $12(7.0)$ & 0.000 \\
\hline$>60$ & 143 & $113(79.0)$ & $30(21.0)$ & \\
\hline \multicolumn{5}{|l|}{ Alcohol use $\mathrm{a}^{\mathrm{a}}$} \\
\hline No & 268 & $238(88.8)$ & $30(\mid I .2)$ & 0.026 \\
\hline Yes & 48 & $36(75)$ & $12(25)$ & \\
\hline
\end{tabular}

(Continued) 
Table I (Continued)

\begin{tabular}{|c|c|c|c|c|}
\hline Variables & Total & $\begin{array}{l}\text { Adherence } \\
\text { N (\%)* }\end{array}$ & $\begin{array}{l}\text { Non- } \\
\text { adherence } \\
\text { N (\%)* }\end{array}$ & P-value \\
\hline \multicolumn{5}{|c|}{ Illegal drug use ${ }^{b}$} \\
\hline Yes & 43 & $27(62.7)$ & $16(37.3)$ & 0.017 \\
\hline No & 273 & $247(90.4)$ & $26(9.6)$ & \\
\hline \multicolumn{5}{|c|}{ Reminder tools ${ }^{c}$} \\
\hline Yes & 287 & $257(89.5)$ & $30(10.5)$ & 0.000 \\
\hline No & 29 & $17(58.6)$ & $12(4 \mid .4)$ & \\
\hline \multicolumn{5}{|c|}{ ART initiation (month) } \\
\hline$<24$ & 166 & l48 (89.1) & $18(10.9)$ & 0.178 \\
\hline$\geq 24$ & 150 & $126(84.0)$ & $24(16.0)$ & \\
\hline \multicolumn{5}{|c|}{ CD4 cell count ${ }^{\mathrm{d}}\left(\right.$ cells $\left./ \mathrm{mm}^{3}\right)$} \\
\hline$<200$ & 56 & $44(78.5)$ & $12(21.6)$ & 0.193 \\
\hline $200-350$ & 148 & 130 (87.8) & $18(12.2)$ & \\
\hline$>350$ & 99 & $87(87.8)$ & $12(12.2)$ & \\
\hline \multicolumn{5}{|c|}{ Adverse effects } \\
\hline Yes & 248 & $208(83.8)$ & $40(16.2)$ & 0.005 \\
\hline No & 68 & $66(97.0)$ & $2(3.0)$ & \\
\hline \multicolumn{5}{|c|}{ Number of tablets per day } \\
\hline$\leq 3$ & 237 & $202(85.3)$ & $35(14.7)$ & 0.180 \\
\hline$>3$ & 79 & 72 (9I.I) & 7 (8.9) & \\
\hline
\end{tabular}

Notes: *Row percentage; a alcohol use: alcohol use in past I month; billegal drug use: illegal drug use in past 6 months prior to study; 'reminder tools: use of any reminder tool to take ART; ${ }^{d} \mathrm{CD} 4$ count: latest available CD4 cell count.

Abbreviation: ART, antiretroviral therapy.

take the medicine at the correct time (Table 1). Some of the most widely used reminder tools were mobile alarm, watch, and support from family members.

A total of $248(78.5 \%)$ participants reported different health complaints that occurred in the month before interview, which could have been caused by either the HIV infection, or the ART (Table 2). Dizziness, skin rash, and

Table 2 Distribution of health complaints among HIV-infected patients receiving ART in the Kathmandu District, 2012

\begin{tabular}{lll}
\hline Health complaints & $\mathbf{N}$ (\%) & P-value** \\
\hline Itching & $72(22.8 \%)$ & 0.433 \\
Headache & $43(13.6 \%)$ & 0.395 \\
Dizziness & $40(12.7 \%)$ & 0.002 \\
Skin rash & $39(12.3 \%)$ & 0.000 \\
Vomiting & $39(12.3 \%)$ & 0.008 \\
Fatigue & $34(10.8 \%)$ & 0.838 \\
Prolonged fever & $32(10.1 \%)$ & 0.185 \\
Arthritis & $23(7.3 \%)$ & 0.500 \\
Persistent cough & $17(5.4 \%)$ & 0.438 \\
Anemia & $16(5.1 \%)$ & 0.395 \\
Pain and numbness & $15(4.7 \%)$ & 0.433 \\
Diarrhea & $10(3.2 \%)$ & 0.525 \\
Others & $13(4.1 \%)$ & 0.725 \\
Insomnia & $9(2.8 \%)$ & 0.845 \\
\hline
\end{tabular}

Notes: *Number overlap (participants could report more than one reason); **comparing frequency between adherent and non-adherent participants.

Abbreviation: ART, antiretroviral therapy. vomiting were significantly more frequently reported among non-adherent participants $(P<0.005)$.

In univariate analyses (Table 3), non-adherence was significantly associated with the travel time to ART centers, alcohol use, illegal drug use, adverse effects, cost

Table 3 Factors associated with non-adherence (univariate and age- and sex-adjusted) among HIV-infected patients in the Kathmandu District, 2012

\begin{tabular}{|c|c|c|}
\hline Variables & $\begin{array}{l}\text { Crude OR } \\
(95 \% \mathrm{Cl})\end{array}$ & $\begin{array}{l}\text { Age and sex adjusted } \\
\text { OR }(95 \% \mathrm{Cl})\end{array}$ \\
\hline$\overline{\text { Age }}$ & $1.03(1.0-1.07)$ & I.03 (0.99-I.07) \\
\hline \multicolumn{3}{|l|}{ Sex } \\
\hline Male & $1.89(0.89-4.02)$ & $1.87(0.88-3.99)$ \\
\hline Female & 1 & 1 \\
\hline \multicolumn{3}{|l|}{ Marital status } \\
\hline Ever married & $1.00(0.45-2.22)$ & $0.62(0.24-1.54)$ \\
\hline Unmarried & $\mathrm{I}$ & $\mathrm{I}$ \\
\hline \multicolumn{3}{|l|}{ Education level } \\
\hline Illiterate & $1.10(0.48-2.54)$ & $\mathrm{I} .23(0.52-2.86)$ \\
\hline Literate & 1 & 1 \\
\hline \multicolumn{3}{|l|}{ Occupation } \\
\hline Unemployed & $1.56(0.76-3.19)$ & $\mathrm{I} .68(0.8 \mathrm{I}-3.47)$ \\
\hline Employed & 1 & $\mathrm{I}$ \\
\hline \multicolumn{3}{|l|}{ Income } \\
\hline Lower tertile & $\mathrm{I} .57(0.70-3.5 \mathrm{I})$ & I.8I (0.79-4.10) \\
\hline Middle tertile & $1.22(0.54-2.79)$ & $1.32(0.57-3.04)$ \\
\hline Higher tertile & 1 & 1 \\
\hline \multicolumn{3}{|l|}{ Family } \\
\hline Without family & $1.29(0.6 \mathrm{I}-2.72)$ & I.II (0.52-2.38) \\
\hline With family & 1 & \\
\hline \multicolumn{3}{|c|}{ Cost of travel to ART center } \\
\hline Lower tertile & $0.35(0.14-0.85)$ & $0.33(0.14-0.82)$ \\
\hline Middle tertile & $0.8 I(0.39-\mid .7 I)$ & $0.73(0.34-1.57)$ \\
\hline Higher tertile & 1 & \\
\hline Travel time to & $1.34(1.13-1.61)$ & $1.39(1.16-1.67)$ \\
\hline \multicolumn{3}{|l|}{ ART center } \\
\hline \multicolumn{3}{|l|}{ Alcohol use } \\
\hline Yes & $2.64(1.24-5.63)$ & $2.76(1.27-5.96)$ \\
\hline No & 1 & 1 \\
\hline \multicolumn{3}{|l|}{ Illegal drug use } \\
\hline Yes & $5.6(2.68-11.78)$ & $5.29(2.49-11.24)$ \\
\hline No & 1 & 1 \\
\hline \multicolumn{3}{|c|}{ Use of reminder tools } \\
\hline No & $6.04(2.63-13.86)$ & $6.04(2.59-14.09)$ \\
\hline Yes & I & 1 \\
\hline \multicolumn{3}{|c|}{ ART initiation (month) } \\
\hline$\geq 24$ & $1.56(0.8 I-3.01)$ & $1.24(0.60-2.57)$ \\
\hline$<24$ & I & \\
\hline \multicolumn{3}{|c|}{ CD4 cell count (cells $/ \mathrm{mm}^{3}$ ) } \\
\hline$\leq 200$ & $1.82(0.86-3.81)$ & $1.89(0.89-4.01)$ \\
\hline$>200$ & 1 & 1 \\
\hline \multicolumn{3}{|l|}{ Adverse effects } \\
\hline Yes & 6.34 (1.49-26.97) & $6.99(1.63-29.98)$ \\
\hline No & $\mathrm{I}$ & 1 \\
\hline \multicolumn{3}{|c|}{ Number of tablets per day } \\
\hline$>3$ & $0.97(0.59-1.59)$ & $0.96(0.59-1.56)$ \\
\hline$\leq 3$ & 1 & 1 \\
\hline
\end{tabular}

Abbreviations: $\mathrm{OR}$, odds ratio; $\mathrm{Cl}$, confidence interval; $\mathrm{ART}$, antiretroviral therapy. 
of travel to ART centers, and no use of reminder tools. A borderline significant association was observed with age. After adjusting for age and sex, the same variables remained significantly associated with non-adherence, and the adjusted ORs were almost unchanged. The final multivariate model included age, sex, travel time to ART centers, alcohol use, illegal drug use, adverse effects, and use of reminder tools (Table 4). A 1-year increase in age increased the odds of non-adherence by 4\% (OR 1.04; 95\% CI 1.00-1.09). An increase in travel time to ART centers of 1 hour was associated with a $38 \%$ increase in the odds of being non-adherent (OR 1.38; 95\% CI 1.12-1.71). On the other hand, the odds of being non-adherent among participants with a history of illegal drug use was almost four times that of participants without a history of illegal drug use (OR 3.98; 95\% CI 1.71-9.24), and the odds of non-adherence were highly increased in participants who reported adverse effects (OR 4.88; 95\% CI 1.09-21.8). The odds of being non-adherent among participants who did not use reminder tools were 3.45 times those of participants who did use a reminder tool (OR 3.45; 95\% CI 1.33-8.91).

\section{Discussion}

To our knowledge, this is the first multi-site study to assess the factors associated with ART adherence among HIVinfected patients receiving free ART at ART centers in the Kathmandu District of Nepal. The overall self-reported ART adherence level for 1 week was $86.7 \%$. Time taken

Table 4 Factors associated with non-adherence (final multivariate model) among $316 \mathrm{HIV}$-infected patients in the Kathmandu District, 2012

\begin{tabular}{|c|c|}
\hline Variables & $\begin{array}{l}\text { Final multivariate model } \\
\text { OR }(95 \% \mathrm{Cl})\end{array}$ \\
\hline Age & $1.04(1.00-1.09)$ \\
\hline \multicolumn{2}{|l|}{ Sex } \\
\hline Male & $2.19(0.92-5.25)$ \\
\hline Female & $\mathrm{I}$ \\
\hline Travel time to ART center & $1.38(1.12-1.71)$ \\
\hline \multicolumn{2}{|l|}{ Alcohol use } \\
\hline Yes & $2.26(0.93-5.44)$ \\
\hline No & I \\
\hline \multicolumn{2}{|l|}{ Illegal drug use } \\
\hline Yes & $3.98(1.71-9.24)$ \\
\hline No & I \\
\hline \multicolumn{2}{|l|}{ Adverse effects } \\
\hline Yes & $4.88(1.09-21.80)$ \\
\hline No & 1 \\
\hline \multicolumn{2}{|l|}{ Use of reminder tools } \\
\hline No & 3.45 (1.33-8.9l) \\
\hline Yes & 1 \\
\hline
\end{tabular}

to reach ART centers, self-reported adverse effects, illegal drug use, and not using reminder tools present barriers to ART adherence.

ART adherence in this study is consistent with previous, similar studies in Nepal, and is comparable to self-reported ART adherence in several other low- and middle-income countries. ${ }^{3,17,19,20}$ The slightly higher ART adherence in this study might be due the assessment of 7-day adherence. It is also possible that adherent patients are more likely to attend their outpatient appointments, and thus more likely to be included in this study sample. However, the $13 \%$ nonadherence observed in the present study constitutes a serious problem in a resource-limited country like Nepal, as the development of treatment resistance will lead to increased hospitalization rates, increased health care costs, reduced productivity, disruption of families and communities, and increased morbidity and mortality. The main reasons participants gave for non-adherence were simply forgetting to take ART and having a busy schedule, which is in accordance with previous findings. ${ }^{12,19,23,24}$

The proportion of men in this study sample was approximately two-fold that of women, which is similar to the proportion of HIV/AIDS cases reported in Nepal. ${ }^{14}$ Sex and marital status did not significantly affect ART adherence. This finding is in agreement with studies elsewhere, ${ }^{12,20,23}$ but in contrast to a previous study in Nepal, ${ }^{17}$ in which HIV-infected women were less likely to adhere to ART. Nevertheless, HIV-infected women in most low- and middle-income countries face several social, psychological, economical, and biological challenges which impact their ability to take medication. Therefore, the challenge to improve access to ART and ART adherence in women remains critical in these countries. ${ }^{3}$

The present study shows that ART adherence decreased significantly with increasing age. However, this finding contrasts with a study by Barclay et al, which showed that patients aged less than 50 years were two times more likely to be non-adherent, ${ }^{25}$ and with studies that showed no association between age and ART adherence. ${ }^{17,19,24,26}$ Such variations could be related to differences between studies in terms of population sampling. Indeed, the number of persons aged 50 years and older living with HIV/AIDS is increasing due to ART. ${ }^{27}$ Therefore, the influence of age may change over time and needs to be further elucidated. The results of this study provide evidence that difficult access to ART in the form of long travel time to ART centers can hinder ART adherence among HIV-infected patients in resource-limited countries. In accordance with this, two Indian studies ${ }^{20,23}$ and two 
African studies ${ }^{12,24}$ showed that traveling from distant places to ART centers was one of the barriers to ART adherence. It has been reported that, despite the extension of ART centers into different regions of Nepal, people living with HIV are unwilling to seek treatment at the nearest health institution due to fear of stigmatization. ${ }^{17}$ In such situations, patients may choose to travel long distances to seek ART services, which may ultimately lead to less ART adherence because of time constraints. In Nepal, traveling long distances to receive treatment is common, and not surprisingly, transportation difficulties have often been reported to be a major hindrance to ART adherence. ${ }^{3}$

Health complaints such as dizziness, skin rash, and vomiting were more frequently reported by non-adherent than adherent participants. This study shows that health complaints due to HIV infection, or as an adverse effect of ART, are associated with non-adherence. This is consistent with findings of several other studies. ${ }^{17,19,24}$ In addition, one meta-analysis showed that varying from mild to severe and from acute to chronic, adverse effects and toxicity of the complex ART drugs was an important reason for nonadherence. ${ }^{28}$ The management of symptoms is a vital part of successful ART adherence. Hence, it is necessary to discuss all potential adverse effects with patients before they begin ART. Moreover, each patient must be assessed individually for readiness to adhere to complex ART regimens. ${ }^{28}$

In contrast to previous findings, ${ }^{28}$ this study found no significant independent association between alcohol use and ART adherence. On the other hand, the high odds of nonadherence among participants with a history of illegal drug use are in agreement with previous studies. ${ }^{3,29-31}$ Patients with a history of substance use are significantly less engaged with their health care provider, and are likely to exhibit a higher rate of treatment refusal. ${ }^{6,28}$ Furthermore, psycho-social problems can be additional factors related to non-adherence among illegal drug users.

This study illustrates the strong association between the use of reminder tools and ART adherence. This supports earlier findings of 4.2-fold greater risk of non-adherence among patients who did not use any reminder tool. ${ }^{8}$ In a review of ART adherence, Mills et al showed that reminders in the form of support from friends and family facilitates successful ART adherence. ${ }^{32}$ In addition, disclosing one's HIV status to others had a positive influence on adherence. . $^{3,28}$

Although many other potential variables were included in this study, they did not show consistent associations with ART adherence. The number of tablets taken per day was not associated with ART adherence in univariate or multivariate analysis. However, several other studies have shown that ART adherence decreases with an increasing number of tablets and number of daily doses. ${ }^{20,33}$ Nevertheless, various studies reported that despite new ART regimens with fewer tablets and daily doses, adherence remains a problem. ${ }^{7,33}$ Objective tools such as pill count, electronic pill caps, and other biological methods are needed in the evaluation of the association between the number of tablets and ART adherence.

Similar to previous studies, ${ }^{17,19,34}$ no significant associations were found between education level, income, marital status, and adherence. Moreover, similar to most, ${ }^{23,24,33}$ but not all ${ }^{20}$ previous studies, the present study showed no significant association between the time since initiating ART and non-adherence.

ART adherence varies over time and between individuals. Therefore, using multiple measures, prospective and mixed studies, including qualitative and quantitative research from delivery sites run by both the public and private sector, are needed to assess the factors associated with ART adherence.

\section{Strengths and limitations}

The strengths of the study include the relatively large and representative sample of HIV-infected patients. Adherence was assessed for the 7 days prior to interview so that participants could accurately recall their behavior, thereby minimizing the chance of recall bias.

The findings may not form an adequate basis for generalization due to the limitations: ART adherence was selfreported, and was assessed in terms of missing doses during the previous 7 days. Other dimensions of ART adherence, such as whether participants took the ART in accordance with dietary instructions, were not explored. It should be mentioned that only patients who personally collected/ refilled their ART at ART centers were included; patients whose ART was delivered to their home by volunteers were not approached. On the other hand, there might be other confounding factors that were not taken into account in this study. Self-reported information might have been influenced by recall bias and the social desirability effect, ie, patients' desire not to disclose non-adherence in order to present themselves as a good patient. ${ }^{35}$ However, selfreported measures are commonly used in both research and clinical care because of their relatively low cost, ease of administration, and good correlation with indirect adherence measures, such as pill count. ${ }^{36}$ Furthermore, this is a crosssectional study, therefore the temporal relationship among 
the variables studied is unknown, and a causal relationship cannot be established.

\section{Conclusion}

The ART adherence results in the present study are encouraging. The findings suggest that travel time to ART centers, selfreported adverse effects, and substance use present additional barriers to ART adherence. On the other hand, having reminder tools to take ART enhanced adherence. Interventions on the individual and community levels, such as community care centers and home-based care, need to be expanded at the village or district level to overcome these barriers. Moreover, health care providers should give clear instructions and proper counseling to patients in order to manage side effects. Patients reporting a history of illegal drug use should be targeted to enhance ART adherence. The use of different electronic devices such as watch and mobile phone should be encouraged as reminder tools to enhance ART adherence.

\section{Acknowledgments}

The Authors thank the participants and the staff members of the ART clinics for their cooperation during data collection. UiT The Arctic University of Norway had provided financial support for this research but had no role in study design, data collection or analysis, report writing, or the decision to publish this research data in a peer-reviewed journal.

\section{Disclosure}

The authors declare that they have no competing interests.

\section{References}

1. UNAIDS. World AIDS Day Report: Joint United Nations Programme on HIV/AIDS. 2011. Available from: http://www.unaids.org/en/media/ unaids/contentassets/documents/unaidspublication/2011/JC2216_ WorldAIDSday_report_2011_en.pdf. Accessed September 13, 2012.

2. Wasti SP, Simkhada P, Teijlingen ER. Antiretroviral treatment programmes in Nepal: Problems and barriers. Kathmandu Univ Med J (KUMJ). 2009;7(27):306-314.

3. Wasti SP, van Teijlingen E, Simkhada P, et al. Factors influencing adherence to antiretroviral treatment in Asian developing countries: a systematic review. Trop Med Int Health. 2012;17(1):71-81.

4. Havlir D, Beyrer C. The beginning of the end of AIDS? N Engl J Med. 2012;367(8):685-687.

5. Horizons/Population Council, International Centre for Reproductive Health and Coast Province General Hospital, Mombasa-Kenya. Adherence to Antiretroviral Therapy in Adults: A Guide for Trainers. Nairobi: Population Council. 2004. Available from: http://www.popcouncil. org/uploads/pdfs/horizons/mombasaarvtrainingguide.pdf. Accessed August 13, 2012.

6. Machtinger EL, Bangsberg DR. Adherence to HIV Antiretroviral Therapy. 2005. Available from: http://hivinsite.ucsf.edu/InSite?page=kb00\&doc=kb-03-02-09. Accessed May 19, 2014.

7. Erah PO, Arute JE. Adherence of HIV/AIDS patients to antiretroviral therapy in a tertiary health facility in Benin City. Afr J Pharm Pharmaco. 2008;2(7):145-152.
8. Molassiotis A, Nahas-Lopez V, Chung WY, Lam SW, Li CK, Lau TF. Factors associated with adherence to antiretroviral medication in HIVinfected patients. Int J STD AIDS. May 2002;13(5):301-310.

9. Steel G, Nwokike J, Joshi M P. Development of a Multi-Method Tool to Measure Art Adherence in Resource-Constrained Settings: the South Africa Experience. Arlington, VA 22203 USA: Center for Pharmaceutical Management 2007. Available from: http://pdf.usaid. gov/pdf_docs/PNADK153.pdf. Accessed July 13, 2013.

10. HIV Drug Resistance, Fact Sheet. World Health Organization. 2011. Available from: http://www.who.int/hiv/facts/WHD2011-HIVdr-fsfinal.pdf. Accessed August 13, 2012.

11. Kahana SY, Rohan J, Allison S, Frazier TW, Drotar D. A metaanalysis of adherence to antiretroviral therapy and virologic responses in HIV-infected children, adolescents, and young adults. AIDS Behav. 2013;17(1):41-60.

12. Wakibi SN, Ng'ang'a ZW, Mbugua GG. Factors associated with nonadherence to highly active antiretroviral therapy in Nairobi, Kenya. AIDS Res Ther. 2011;8:43.

13. HIV/AIDS in Nepal; 2012. Available from: http://www.worldbank. org/en/news/feature/2012/07/10/hiv-aids-nepal. Accessed May 19, 2014.

14. NCASC. Nepal Country Progress Report. National Centre for AIDS and STD Control. 2012. Available from: http://www.unaids.org/en/ dataanalysis/knowyourresponse/countryprogressreports/2012countries/ ce_NP_Narrative_Report.pdf. Accessed July 13, 2013.

15. NCASC. National Antiretroviral Therapy Guidelines. National centre for AIDS and STD Control. 2009. Available from: http://www.who.int/ hiv/pub/guidelines/nepal_art.pdf. Accessed September 13, 2012.

16. NCASC. Factsheet No 4: Antiretroviral Therapy (ART) Services in Nepal, As of July, 2012. Kathmandu: National centre for AIDS and STD Control. 2012. Available from: http://www.ncasc.gov.np/uploaded/ facts_n_figure/FactSheet_2012/Factsheet\%204_ART_2012_Nov_25. pdf. Accessed August 13, 2012.

17. Wasti SP, Simkhada P, Randall J, Freeman JV, van Teijlingen E. Factors influencing adherence to antiretroviral treatment in Nepal: a mixed-methods study. PloS One. 2012;7(5):e35547.

18. Sharma S, Khadga P, Dhungana G, Chitrakar U. Medication adherence to antiretroviral therapy among patients visiting antiretroviral therapy center at Tribhuvan University Teaching Hospital, Kathmandu Nepal. Kathmandu Univ Med J. 2013;11(41):50-53.

19. Bam K, Karki D, Lohani S, Thapa R, Aryal U, Pathak L. Adherence to anti-retroviral therapy among people living with HIV and AIDS in Far West, Nepal. Asian Journal of Medical Sciences. 2011;2:7-13.

20. Cauldbeck MB, O'Connor C, O'Connor MB, et al. Adherence to antiretroviral therapy among HIV patients in Bangalore, India. AIDS Res Ther. 2009;6:7.

21. Do HM, Dunne MP, Kato M, Pham CV, Nguyen KV. Factors associated with suboptimal adherence to antiretroviral therapy in Viet Nam: a cross-sectional study using audio computer-assisted self-interview (ACASI). BMC Infect Dis. 2013;13(1):154.

22. Potchoo Y, Tchamdja K, Balogou A, Pitche VP, Guissou IP, Kassang EK. Knowledge and adherence to antiretroviral therapy among adult people living with HIV/AIDS treated in the health care centers of the association "Espoir Vie Togo" in Togo, West Africa. BMC Clin Pharmacol. 2010;10:11.

23. Sarna A, Pujari S, Sengar AK, Garg R, Gupta I, Dam Jv. Adherence to antiretroviral therapy and its determinants amongst HIV patients in India. Indian J Med Res. 2008;127(1):28-36.

24. Markos E, Worku A, Davey G. Adherence to ART in PLWHA at Yirgalem Hospital, South Ethopia. Ethiop J Health Dev. 2008;22(2): 174-179.

25. Barclay TR, Hinkin CH, Castellon SA, et al. Age-associated predictors of medication adherence in HIV-positive adults: health beliefs, self-efficacy, and neurocognitive status. Health Psychol. 2007;26(1):40-49.

26. Talam NC, Gatongi P, Rotich J, Kimaiyo S. Factors affecting antiretroviral drug adherence among HIV/AIDS adult patients attending HIV/ AIDS clinic at Moi Teaching and Referral Hospital, Eldoret, Kenya. East Afr J Public Health. 2008;5(2):74-78. 
27. CDC. HIV/AIDS among Persons Aged 50 and Older: Centers for Disease control and prevention. 2008. Available from: http://www.cdc.gov/hiv/ pdf/library_factsheet_HIV_among_PersonsAged50andOlder.pdf. Accessed September 13, 2012.

28. Ortego C, Huedo-Medina TB, Llorca J, et al. Adherence to highly active antiretroviral therapy (HAART): a meta-analysis. AIDS Behav. 2011;15(7):1381-1396.

29. Arnsten JH, Li X, Mizuno Y, et al. Factors associated with antiretroviral therapy adherence and medication errors among HIV-infected injection drug users. J Acquir Immune Defic Syndr. 2007;46(2): S64-S71.

30. Thames AD, Moizel J, Panos SE, et al. Differential predictors of medication adherence in HIV: findings from a sample of African American and Caucasian HIV-positive drug-using adults. AIDS Patient Care STDS. 2012;26(10):621-630.

31. Berg KM, Demas PA, Howard AA, Schoenbaum EE, Gourevitch MN, Arnsten JH. Gender differences in factors associated with adherence to antiretroviral therapy. J Gen Intern Med. 2004;19(11):1111-1117.
32. Mills EJ, Nachega JB, Bangsberg DR, et al. Adherence to HAART: a systematic review of developed and developing nation patient-reported barriers and facilitators. PLoS Med. 2006;3(11):e438.

33. Aragonés C, Sánchez L, Campos JR, Pérez J. Antiretroviral therapy adherence in persons with HIV/AIDS in Cuba. MEDICC Rev. 2011;13(2):17-23.

34. Byakika-Tusiime J, Oyugi JH, Tumwikirize WA, Katabira ET, Mugyenyi PN, Bangsberg DR. Adherence to HIV antiretroviral therapy in HIV+ Ugandan patients purchasing therapy. Int J STD AIDS. 2005;16(1):38-41.

35. Wagner G, Miller LG. Is the influence of social desirability on patients' self-reported adherence overrated? J Acquir Immune Defic Syndr. 2004;35(2):203-204.

36. Simoni JM, Kurth AE, Pearson CR, Pantalone DW, Merrill JO, Frick PA. Self-report measures of antiretroviral therapy adherence: A review with recommendations for HIV research and clinical management. AIDS Behav. 2006;10(3):227-245.
HIV/AIDS - Research and Palliative Care

\section{Publish your work in this journal}

HIV/AIDS - Research and Palliative Care is an international, peerreviewed open-access journal focusing on advances in research in HIV, its clinical progression and management options including antiviral treatment, palliative care and public healthcare policies to control viral spread. The journal welcomes original research, basic science,

\section{Dovepress}

clinical \& epidemiological studies, reviews \& evaluations, expert opinion \& commentary, case reports \& extended reports. The manuscript management system is completely online and includes a very quick and fair peer-review system. Visit http://www.dovepress.com/ testimonials.php to read real quotes from published authors. 